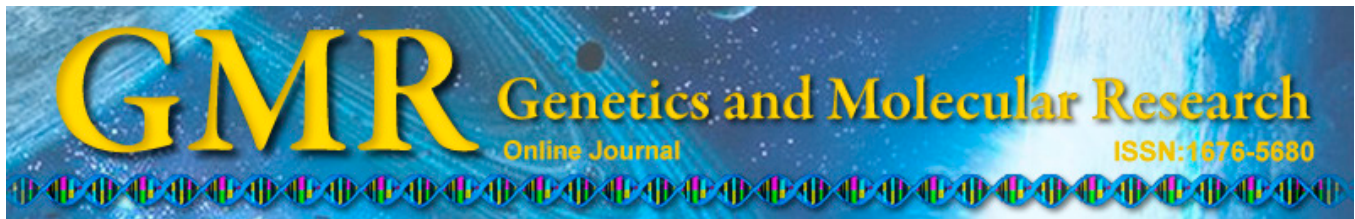

\title{
Genetic diversity and pathogenicity differentiation of Sclerotinia sclerotiorum on rapeseed (Brassica napus L.) in Anhui Province, China
}

\author{
D.F. Xu ${ }^{1,2}$, X.L. Li ${ }^{1}$, Y.M. Pan ${ }^{1}$, Y.L. Dai ${ }^{1}$, P. Li ${ }^{1}$, F.X. Chen ${ }^{1}$, H.J. Zhang ${ }^{1}$, \\ M. Guo ${ }^{1}$ and Z.M. Gao ${ }^{1}$ \\ ${ }^{1}$ College of Plant Protection, Anhui Agricultural University, Hefei, China \\ ${ }^{2}$ Institute of Tobacco, Anhui Academy of Agricultural Sciences, Hefei, China \\ Corresponding author: Z.M. Gao \\ E-mail: gzm@ahau.edu.cn / gaozhimou@126.com
}

Genet. Mol. Res. 13 (4): 10704-10713 (2014)

Received October 22, 2013

Accepted March 18, 2014

Published December 18, 2014

DOI http://dx.doi.org/10.4238/2014.December.18.12

\begin{abstract}
The pathogenicity of 47 isolates of Sclerotinia sclerotiorum from oilseed rape (Brassica napus L.) in Anhui, China, was tested by detached leaf inoculation using the susceptible rape cultivar Wanyou-14. All isolates were pathogenic to the cultivar and could be grouped into 3 categories based on the lesion length on the leaves tested: weak pathogenicity type, intermediate pathogenicity type, and strong pathogenicity type. This suggested that there was differentiation in the pathogenicity among the strains tested of $S$. sclerotiorum. Additionally, the intraspecific DNA polymorphisms among 47 strains of $S$. sclerotiorum were investigated by screening 40 pairs of inter-simple sequence repeat (ISSR) primers. Unweighted pairgroup method with arithmetic average cluster analysis of these ISSR data distinguished all strains from each other and revealed considerable genetic variability among them. These strains were classified into 7 clusters according to their branching in the dendrogram, and partial
\end{abstract}


correlation was observed between the genetic polymorphisms and the pathogenicity of $S$. sclerotiorum strains.

Key words: Sclerotinia sclerotiorum; Oilseed rape; Pathogenicity; Inter-simple sequence repeat (ISSR); Genetic diversity

\section{INTRODUCTION}

Sclerotinia sclerotiorum (Lib.) de Bary, one of the most devastating and cosmopolitan plant pathogens, can cause numerous diseases of over 400 species of plants worldwide (Boland and Hall, 1994; Bolton et al., 2006). Not only can it infect dicotyledonous crops such as oilseed rape, soybean, sunflower, and various vegetables, but it can also infect monocotyledonous species such as onion and tulip (Boland and Hall, 1994), leading to millions of dollars in losses around the world annually due to the damage caused by these diseases (Purdy, 1979; Subbarao, 1998; Tahtamouni et al., 2006).

Rapeseed (Brassica napus L.) is a main oil crop in Anhui Province, one of the main production areas of rape in China, with an annual total output of approximately 1.8 billion kilograms (Rong, 2009). S. sclerotiorum caused serious stem rots in oilseed rape, and the diseases have proven difficult to control with the inadequate host genetic resistance to this fungus (Williams et al., 2011). In recent years, the disease led to approximately 20 to $50 \%$ loss of output in ordinary fields, and in the severely diseased fields, the loss was over $50 \%$ in Anhui, China (Rong, 2009). Clearly, the disease caused by S. sclerotiorum has become a serious limitation to rapeseed production in Anhui.

S. sclerotiorum, a necrotrophic fungus that is able to feed on dead cells, is one of the most non-specific, omnivorous, and successful plant pathogens (Purdy, 1979; Boland and Hall, 1994). The fungus has 2 main pathogenicity factors, oxalic acid and hydrolytic enzymes, which act in concert to macerate plant tissues and generate necrosis. The secreted lytic enzymes facilitate penetration, colonization, and maceration, and they generate the important sources of nutrients (Bolton et al., 2006). Oxalic acid secreted by the fungus can acidify the apoplastic space, sequester calcium, and interfere with plant defenses; therefore, it appears to be an essential determinant of pathogenicity (Maxwell and Lumsden, 1970; Hegedus and Rimmer, 2005).

Generally, the understanding of the epidemiology and genetic diversity of the regional pathogen population have been regarded as the most effective strategy to control plant diseases and supervise the generation of resistant cultivars. However, little is known about the genetic diversity and pathogenicity differentiation of S. sclerotiorum on oilseed rape (Brassica napus L.) in Anhui to date.

In recent years, a variety of molecular techniques, such as amplified fragment length polymorphism (AFLP), random amplified polymorphic DNA (RAPD), and simple sequence repeat (SSR), have been used to investigate the genetic diversity of plant pathogen populations (Mukai et al., 1995; Hill et al., 1996; Bai et al., 1997; Jiang et al., 2007). Because of the productive polymorphic fragments by the AFLP assay, AFLP seems to be a more effective polymerase chain reaction (PCR)-based technique than others such as RAPD. However, inter-simple sequence repeats (ISSRs), which are based on primers that are complementary to microsatellite regions by PCR and was believed to be a useful and reliable new method to determine genetic polymorphism between accessions (Meyer et al., 1993; Zietkiewicz et al., 
1994), can produce highly reproducible polymorphic bands, similar to the AFLP technique but a simpler method that costs less than that using AFLP (McGregor et al., 2000). ISSR molecular markers have been successfully used to determine the genetic variability of different phytopathogenic fungi, such as Phytophthora capsici (Li et al., 2012), P. cactorum (Hantula et al., 2000), Macrophomina phaseolina (Jana et al., 2005), and Fusarium oxysporum f. sp. radicis-lycopersici (Balmas et al., 2005). ISSR is more advantageous than other techniques in showing intraspecies and interspecies differences (Arslan and Tamkoç, 2011). In this report, the ISSR assay was used to develop molecular markers to reveal the genetic diversity and pathogenesis differentiation of $S$. sclerotiorum populations on oilseed rape.

\section{MATERIAL AND METHODS}

\section{Strains and cultivation}

Forty-seven strains of S. sclerotiorum were isolated and collected from oilseed rape cultivated in areas of Anhui Province (Table 1) and were stored in the Fungal Laboratory of Anhui Agricultural University. Strains were inoculated on potato dextrose agar medium. Two pieces of fresh fungal mycelium plugs from each of the isolates tested were then inoculated in potato dextrose broth liquid medium and kept at $25^{\circ} \mathrm{C}$ with shaking at $150 \mathrm{rpm}$ for 7 days. The mycelia were harvested by filtration through sterile Miracloth and were stored at $-20^{\circ} \mathrm{C}$ for later use.

\section{Pathogenicity tests}

The in vitro pathogenicity tests were performed with a susceptible rapeseed cultivar, Wanyou-14, according to Huang and Li (2009). The upper healthy leaves with similar sizes were collected in the early flowering stage of rapeseed and then placed on Petri dishes $(9 \mathrm{~cm})$ with a wet absorbent paper on the bottom to maintain moisture. Fresh hyphal plugs $(5 \mathrm{~mm}$ in diameter) were inoculated on the detached rape leaves, with 2 hyphal plugs at the 2 sides of the main vein on each leaf. Eight leaves were inoculated for each strain. The inocula were kept at $25^{\circ} \mathrm{C}$ with a 12-h photoperiod, and the disease lesion diameters were measured $72 \mathrm{~h}$ after inoculation. The pathogenic tests were repeated 3 times. The experimental data were analyzed by analysis of variance (SAS 8.1), and the pathogenicity of the isolates tested of S. sclerotiorum was evaluated based on the average lesion diameters on inoculated plants (Huang and Li, 2009).

\section{Reagents and primers}

Taq DNA polymerase was from Takara Bio. Inc. (DR100A; Dalian, China) and Sangon Biotech Co., Ltd (ET-101; Shanghai, China). dNTPs and DNA marker were from Sangon Biotech Co., Ltd. Forty ISSR primers, offered by the University of British Columbia from 100 ISSR primers (http://www.michaelsmith.ubc.ca), were selected for further analysis based on the characteristic DNA repeat sequences in plant pathogenic fungi.

\section{DNA extraction}

DNA was isolated and extracted from the mycelia of 47 strains of S. sclerotiorum using cetyltrimethylammonium bromide (Stewart and Via, 1993). The DNA extracted was 
stored at $4^{\circ} \mathrm{C}$ for $16 \mathrm{~h}$ and then was stored at $-20^{\circ} \mathrm{C}$. The DNA samples were quantified at 260 $\mathrm{nm}$ and $280 \mathrm{~nm}$ using a spectrophotometer. The light-absorption value was checked between 1.7 and 2.0 to examine the purity of DNA. The final concentration of each DNA sample was diluted to $50 \mathrm{ng} / \mu \mathrm{L}$.

Table 1. Geographical origin and pathogenicity of isolates tested of Sclerotinia sclerotiorum on oilseed rape.

\begin{tabular}{|c|c|c|c|c|}
\hline Culster & Code No. & Isolate No. & Counties of origin & Pathogenicity \\
\hline \multirow[t]{6}{*}{ I } & 1 & NGB5 & Ningguo & I \\
\hline & 2 & NGA6 & Ningguo & $\mathrm{S}$ \\
\hline & 22 & XJDB8 & Jingde & $\mathrm{S}$ \\
\hline & 27 & SX-6 & Shouxian & $\mathrm{S}$ \\
\hline & 39 & FD-1 & Feidong & I \\
\hline & 25 & SX-11 & Shouxian & W \\
\hline \multirow[t]{5}{*}{ II } & 11 & NGB-1-3 & Ningguo & I \\
\hline & 12 & NGB-1-2 & Ningguo & W \\
\hline & 13 & NGA5 & Ningguo & I \\
\hline & 38 & WW-1 & Wuwei & $\mathrm{S}$ \\
\hline & 40 & FD-2 & Feidong & I \\
\hline \multirow[t]{2}{*}{ III } & 31 & LJE-1-3 & Lujiang & $\mathrm{S}$ \\
\hline & 45 & NL-1 & Nanling & $\mathrm{S}$ \\
\hline \multirow[t]{10}{*}{ IV } & 5 & NGA4 & Ningguo & I \\
\hline & 35 & WW-2 & Wuwei & I \\
\hline & 43 & LA-1 & Liuan & W \\
\hline & 18 & JDA17 & Jingde & $\mathrm{S}$ \\
\hline & 30 & LJA-5-2 & Lujiang & I \\
\hline & 19 & JDA15 & Jingde & I \\
\hline & 47 & WH-2 & Wuhu & $\mathrm{S}$ \\
\hline & 26 & SX-2 & Shouxian & $\mathrm{S}$ \\
\hline & 20 & JDA19 & Jingde & $\mathrm{S}$ \\
\hline & 7 & NGC2 & Ningguo & I \\
\hline \multirow[t]{11}{*}{ V } & 10 & NGC10 & Ningguo & I \\
\hline & 41 & HF-1 & Hefei & I \\
\hline & 34 & WJC-2 & Wangjiang & $\mathrm{S}$ \\
\hline & 44 & HQ-1 & Huoqiu & I \\
\hline & 46 & FC-1 & Fanchang & $\mathrm{S}$ \\
\hline & 14 & TC-15 & Tongcheng & $\mathrm{S}$ \\
\hline & 21 & XJDB6 & Jingde & $\mathrm{S}$ \\
\hline & 23 & SX-9-1 & Shouxian & $\mathrm{S}$ \\
\hline & 16 & TC-A-1 & Tongcheng & I \\
\hline & 17 & TC-E-3 & Tongcheng & $\mathrm{S}$ \\
\hline & 8 & NGB2 & Ningguo & $\mathrm{S}$ \\
\hline \multirow[t]{6}{*}{ VI } & 37 & WWB8 & Wuwei & $\mathrm{S}$ \\
\hline & 42 & XC-1 & Xuancheng & $\mathrm{S}$ \\
\hline & 32 & LJD-5-2 & Lujiang & $\mathrm{S}$ \\
\hline & 36 & WWD3 & Wuwei & I \\
\hline & 3 & NGB1 & Ningguo & $\mathrm{S}$ \\
\hline & 29 & SX-8-1 & Shouxian & I \\
\hline \multirow[t]{6}{*}{ VII } & 4 & $\mathrm{NGC1}$ & Ningguo & $\mathrm{S}$ \\
\hline & 6 & NGB-1-1 & Ningguo & I \\
\hline & 24 & SX-5 & Shouxian & I \\
\hline & 28 & SX-3 & Shouxian & $\mathrm{S}$ \\
\hline & 33 & WJB-3 & Wangjiang & $\mathrm{S}$ \\
\hline & 9 & NGA19 & Ningguo & I \\
\hline
\end{tabular}

${ }^{\#} \mathrm{~S}, \mathrm{~W}$, and I stand for strong pathogenicity type, weak pathogenicity type, and intermediate pathogenicity type, respectively.

\section{ISSR-PCR system}

ISSR-PCR was performed in a total volume of $25 \mu \mathrm{L}$ containing $0.20 \mu \mathrm{L} 0.5$ units/ $\mu \mathrm{L}$ Taq DNA polymerase, $0.1 \mu \mathrm{L} 10 \mu \mathrm{M}$ primer, $1.20 \mu \mathrm{L} 2.5 \mathrm{mM}$ dNTPs, $0.5 \mu \mathrm{L} 50 \mathrm{ng} /$ 
$\mu \mathrm{L}$ DNA, and $2.5 \mu \mathrm{L} 10 \mathrm{X}$ buffer $\left(\mathrm{Mg}^{2+}\right)$. Amplification was conducted for an initial step of denaturation for $5 \mathrm{~min}$ at $94^{\circ} \mathrm{C} ; 35$ cycles of denaturation for $30 \mathrm{~s}$ at $94^{\circ} \mathrm{C}, 60 \mathrm{~s}$ at an appropriate annealing temperature, and extension for $60 \mathrm{~s}$ at $72^{\circ} \mathrm{C}$; and a final extension step of $10 \mathrm{~min}$ at $72^{\circ} \mathrm{C}$. Amplified products were separated on $2 \%$ agarose gels in Tris-borateethylenediaminetetraacetic acid buffer and stained with ethidium bromide.

\section{Data scoring and analysis}

The PCR fragments were scored for the presence (1) or absence (0) of homologous bands. The matrices of the ISSR genotypes were assembled and used in the statistical analysis. Using Jaccard's coefficient, a cluster analysis was performed from the similarity data to construct a dendrogram with the unweighted pair-group method by arithmetic average (UPGMA) matrices. The numerical taxonomy and multivariate analysis system (NTSYSPC V.2.1) program package for personal computer (Rohlf, 2000) was used for the statistical analysis of the data.

\section{RESULTS}

\section{Pathogenicity tests}

The pathogenicity of S. sclerotiorum isolates from oilseed rape was determined on the susceptible rape cultivar Wanyou-14 by detached leaf inoculation. The lesion lengths caused by the isolates on the leaves tested were measured 3 days after inoculation, and the isolates could be grouped into 3 categories based on the lesion length on the leaves tested: weak pathogenicity type $(0$ to $1.0 \mathrm{~cm})$, intermediate pathogenicity type $(1.1$ to $3.0 \mathrm{~cm})$, and strong pathogenicity type $(>3 \mathrm{~cm})$ (Table 1$)$. The results showed that all $S$. sclerotiorum strains tested could infect the leaves of rape, but there were obvious differences in lesion expansion. Such differences suggested that the tested strains of S. sclerotiorum had differential pathogenicity. The results also showed that different strains from the same geographical origin had different pathogenicity, while the strains with the same pathogenicity type might be from different geographical origins. This suggested that the pathogenicity of S. sclerotiorum strains was not related to their geographical origins.

\section{ISSR analysis}

ISSR analysis was carried out using 40 primers, and then 12 primers with rich polymorphisms and differences were screened to detect polymorphisms of these 47 strains of $S$. sclerotiorum. Two examples of the banding profiles of DNA of isolates using primer P59 and primer P15 are shown in Figures 1 and 2, respectively. In total, 136 distinct bands, which were consistent in repeated amplifications, were amplified using the DNA from all isolates. One hundred twenty-five polymorphic bands were obtained that ranged in size from 0.1 to $2 \mathrm{~kb}$. The proportion of polymorphic bands ranged from 83\% (UBC866) to 100\% (UBC807, P9, and P10), with an average proportion of $92 \%$. The number of ISSR fragments produced per primer varied between 6 and 17, with an average of 11 bands per primer. The steady polymorphic bands were produced by 12 primers (Table 2 ). 


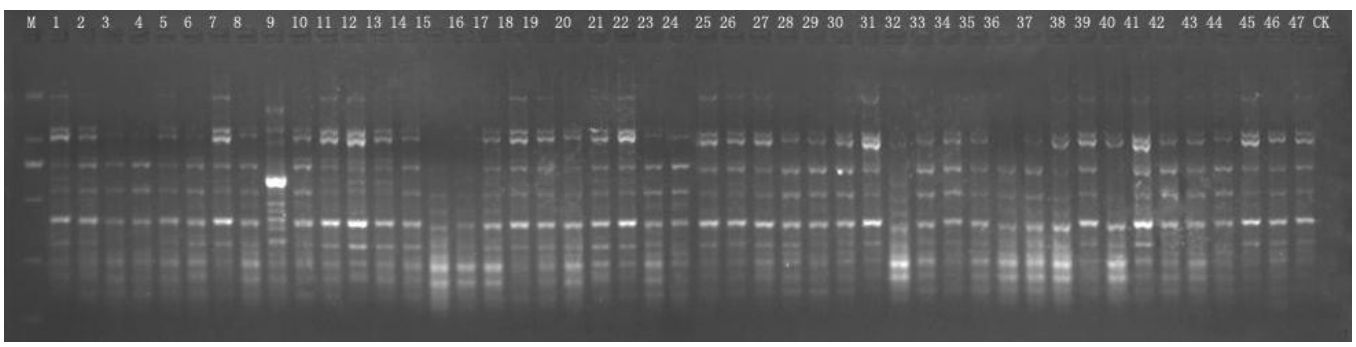

Figure 1. Genetic fingerprints of 47 Sclerotinia sclerotiorum isolates with primer P59. Lane M= DL 2000 marker. Lanes 1-47 are isolate 1, 2, 3, ..., 47 in turn, respectively (Table 1). ISSR-PCR amplification electrophoresis was done on $2 \%(\mathrm{w} / \mathrm{v})$ agarose gels at $100 \mathrm{~V}$ for $2 \mathrm{~h}$ and stained with ethidium bromide.

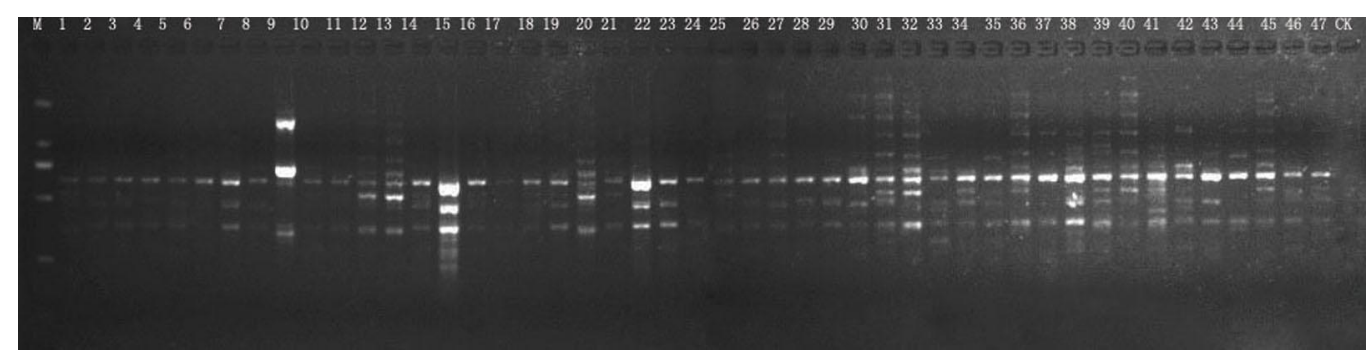

Figure 2. Genetic fingerprints of 47 Sclerotinia sclerotiorum isolates with primer P15. Lane M= DL 2000 marker. Lanes 1-47 are isolate 1, 2, 3, ...., 47 in turn, respectively (Table 1). ISSR-PCR amplification electrophoresis was done on $2 \%(\mathrm{w} / \mathrm{v})$ agarose gels at $100 \mathrm{~V}$ for $2 \mathrm{~h}$ and stained with ethidium bromide.

Table 2. Properties of ISSR primers used for amplification of Sclerotinia sclerotiorum isolates on oilseed rape in the study of genetic diversity in Anhui Province of China.

\begin{tabular}{lccccc}
\hline Primer & Sequence 5'-3' & Total number of bands & Polymorphic bands & Unique bands & Polymorphic band percentage (\%) \\
\hline UBC807 & $(\mathrm{AG})_{8} \mathrm{~T}$ & 9 & 9 & 1 & 100 \\
UBC808 & $(\mathrm{AG})_{8} \mathrm{C}$ & 12 & 11 & 1 & 92 \\
UBC810 & $(\mathrm{GA})_{8} \mathrm{~T}$ & 10 & 9 & 2 & 90 \\
UBC811 & $(\mathrm{GA})_{8} \mathrm{C}$ & 16 & 15 & 2 & 94 \\
UBC825 & $(\mathrm{AC})_{8} \mathrm{~T}$ & 11 & 10 & 6 & 91 \\
UBC841 & $(\mathrm{GA})_{8} \mathrm{YC}$ & 11 & 10 & 1 & 91 \\
UBC866 & $(\mathrm{CTC})_{6}$ & 6 & 5 & 0 & 83 \\
P9 & $(\mathrm{GACA})_{4}$ & 8 & 8 & 1 & 100 \\
P10 & $(\mathrm{GA})_{8} \mathrm{TG}$ & 7 & 7 & 0 & 100 \\
P11 & $(\mathrm{AG})_{8} \mathrm{C}$ & 17 & 15 & 0 & 88 \\
P15 & $\mathrm{G}(\mathrm{ACAG})_{3} \mathrm{ACAC}$ & 13 & 11 & 2 & 85 \\
P59 & $(\mathrm{AG})_{8}$ YC & 16 & 15 & 2 & 94 \\
\hline
\end{tabular}

\section{ISSR cluster analysis}

Using the amplification of 136 spectral bands with 12 ISSR primers, the genetic similarity coefficients of strains of $S$. sclerotiorum of rape were calculated using NTSYS2.1, and dendrograms of strains were constructed by UPGMA analysis. The genetic similarity coefficients ranged from 0.56 to 0.91 (Figure 3 ). When genetic similarity coefficient was 0.81 , 
the strains tested were divided into 7 clusters. Cluster I comprised 6 strains from 4 different geographical origins. Though the 6 strains had different geographical origins, they clustered together. Especially for strains 22 (XJDB8) and 27 (SX-6), the geographic origins of the 2 strains were relatively far from each other, but their genetic similarity were the highest (0.91). Additionally, these 2 strains were the strong pathogenicity type. Cluster II grouped 5 strains from 3 different geographical origins. Although the strains were from 3 different geographical origins, they had a similar pathogenicity (intermediate pathogenicity type). Cluster III included 2 strains, 31 (LJE-1-3) and 45 (NL-1), which were from different geographical origins but were both the strong pathogenicity type. Cluster IV and cluster V comprised 10 and 11 strains, respectively. There were 7 and 8 different geographical origins in cluster IV and V, respectively. However, the pathogenicity of strains in cluster IV tended to be the intermediate pathogenicity type, and that of cluster $\mathrm{V}$ tended to be the strong pathogenicity type. Cluster VI was composed of strains 37 (WWB8) and 42 (XC-1), which were from different locations, and they were the strong pathogenicity type. Finally, cluster VII grouped 2 strains, 4 (NGC1) and 6 (NGB-1-1). One was the strong pathogenicity type and the other was the intermediate pathogenicity type. As a whole, strains of the same region were divided into different branches, which explained why the ISSR polymorphisms of strains of S. sclerotiorum had no significant correlation with their geographical origins. The strains of the same pathogenicity were nearly clustered together; therefore, the polymorphisms of strains of S. sclerotiorum were partly correlated with their pathogenicity (Table 1, Figure 3).

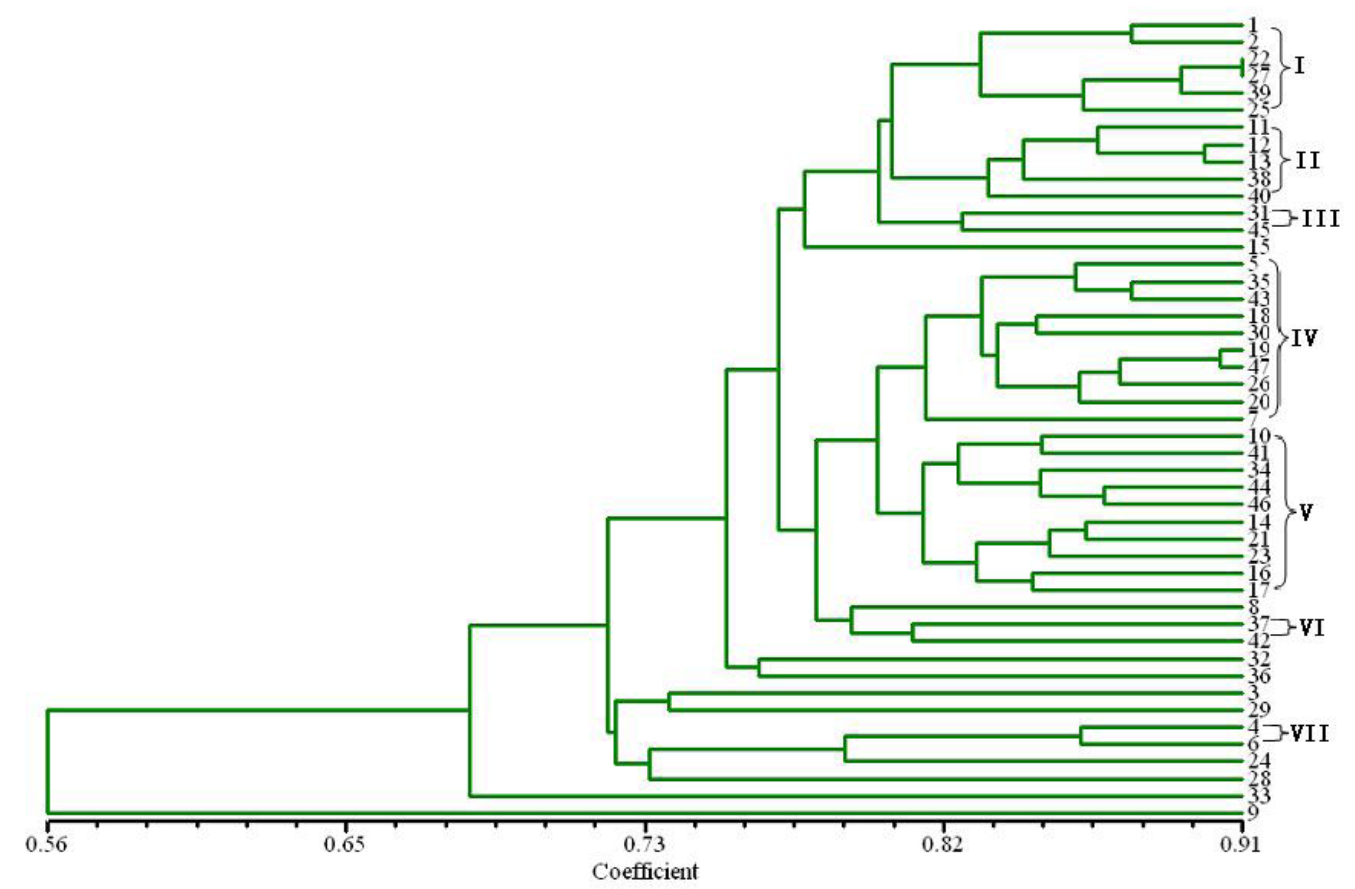

Figure 3. UPGMA cluster analysis of the data from DNA amplification of 47 isolates of Sclerotinia sclerotiorum from oilseed rape with ISSR. The number $1,2,3, \ldots \ldots, 47$ stands for isolate 1 , isolate 2 , isolate $3, \ldots \ldots$, and isolate 47 in turn, respectively (Table 1). 


\section{DISCUSSION}

Researchers have performed several studies evaluating the artificial inoculation of $S$. sclerotiorum and its correlation with disease incidence in the field. In the greenhouse, the results of the inoculating method of detached leaves were notably correlated with disease incidence (Wegulo et al., 1998). Results from this method were also moderately correlated with disease incidence in the field (Kim et al., 2000). This research used the detached leaf inoculation method with an accordant inoculum size and site, and the external conditions, especially weather, had little influence. Therefore, the pathogenicity was evaluated by the lesion size that was caused by different strains of $S$. sclerotiorum. The lesions that were caused by 47 strains varied in size, which indicated different levels of pathogenicity of different strains tested, suggesting that there was significant differentiation in pathogenicity among the isolates of S. sclerotiorum on oilseed rape in Anhui Province, China. This provides experimental evidence and useful reference data for the reasonable use of disease-resistant varieties of rape for disease control.

Some molecular studies have been performed to identify genetic polymorphisms of S. sclerotiorum, and highly significant genetic variation was found among and within populations. With RAPD, Sun et al. (2005) compared and evaluated the polymorphism of S. sclerotiorum populations on rape from China, Poland, and Russia. The polymorphism of strains from China showed a high level of genetic diversity, while the polymorphism of strains from Europe showed a low level of genetic diversity. The polymorphism of a small set of S. sclerotiorum isolates from sunflower in China was analyzed by RAPD, and isolates were divided into 5 groups (Yu et al., 2006). The genetic variation of S. sclerotiorum isolates in Turkey was assessed by microsatellite and morphological markers, and a genotypic diversity level of $63 \%$ within the fungal population was found (Mert-Türk et al., 2007). In 2009, SRAP was used to analyze the polymorphism of $S$. sclerotiorum isolates from sunflower in Canada and Inner Mongolia, China. A high degree of genetic diversity existed within and among the S. sclerotiorum populations (Li et al., 2009).

In this study, the 14 populations from rape cultivation areas in Anhui Province, China, were divided into 7 clusters by UPGMA analysis of ISSR markers when the genetic similarity coefficient was 0.81 . Although strains were from the same $S$. sclerotiorum population, they were not always clustered into the same group, especially the isolates of population 9 (NGA19) from Ningguo, which formed a population that was significantly differentiated from other populations. Perhaps this differentiation was the result of a genetic mutation or the region was invaded and attacked by a different $S$. sclerotiorum strain. Consequently, the genetic polymorphisms of the S. sclerotiorum strains were not correlated with the geographical origin. Sun (2005) reported that the geographic distance between Canadian and Polish populations of $S$. sclerotiorum was large, but the relationship between them was very close. The results showed that isolates 22 (XJDB8) from Jingde and 27 (SX-6) from Shouxian were clustered in the same lineage without differentiation. Though the geographic distance was large, they had the same strong pathogenicity. The strains of 31 (LJE-1-3) and 45 (NL-1), and 37 (WWB8) and 42 (XC1) were from different origins, but they were grouped together, respectively, possibly because both populations were near in geographic distance or had the same strong pathogenicity.

The analysis of the diversity and pathogenicity of S. sclerotiorum populations showed that genetically diverse populations of S. sclerotiorum caused the epidemic of oilseed rape stem rot in Anhui Province, China. Regardless of geographic location, the strains were clustered in groups by similar pathogenicity. Therefore, one of the most effective measures of dis- 
ease control should be the use of resistant cultivars. In this study, potential diagnostic markers on the genetic basis of pathogenicity are highlighted, and additional insights into the molecular evolution of rape pathogens are provided. To our knowledge, this is the first time that ISSR markers have been used to determine the genetic diversity of S. sclerotiorum, which has not been studied as much as other plant pathogens.

The results in this study will contribute to the understanding of the diseases caused by S. sclerotiorum and also serve as a baseline of information for monitoring S. sclerotiorum population evolution in Anhui, China.

\section{ACKNOWLEDGMENTS}

Research supported by the commonwealth specialized research fund of the China Agriculture Ministry (Grant \#201103016) and the special foundation for modern industry (oilseed rape) of Anhui Province. We thank Ningxin Gao and Yucui Mu for their help collecting Sclerotinia sclerotiorum isolates and Yongxia Qi for assistance with ISSR analysis.

\section{REFERENCES}

Arslan E and Tamkoç A (2011). The application of ISSR-PCR to determine the genetic relationship and genetic diversity between narrow leaved bluegrass (Poa angustifolia) and rough bluegrass (Poa trivialis) accessions. Turk. J. Biol. 35: 415-423.

Bai D, Brandle J and Reeleder R (1997). Genetic diversity in North American ginseng (Panax quinquefolius L.) grown in Ontario detected by RAPD analysis. Genome 40: 111-115.

Balmas V, Scherm B, Primo PD and Rau D (2005). Molecular characterisation of vegetative compatibility groups in Fusarium oxysporum f. sp. radicis-lycopersici and f. sp. lycopersici by random amplification of polymorphic DNA and microsatellite-primed PCR. Eur. J. Plant Pathol. 111: 1-8.

Boland GJ and Hall R (1994). Index of plant hosts of Sclerotinia sclerotiorum. Can. J. Plant Pathol. 16: 93-108.

Bolton MD, Thomma BP and Nelson BD (2006). Sclerotinia sclerotiorum (Lib.) de Bary: biology and molecular traits of a cosmopolitan pathogen. Mol. Plant Pathol. 7: 1-16.

Hantula J, Lilja A, Nuorteva H and Parikka P (2000). Pathogenicity, morphology and genetic variation of Phytophthora cactorum from strawberry, apple, rhododendron, and silver birch. Mycol. Res. 104: 1062-1068.

Hegedus DD and Rimmer SR (2005). Sclerotinia sclerotiorum: when "to be or not to be" a pathogen? FEMS Microbiol. Lett. 251: 177-184.

Hill M, Witsenboer H, Zabeau M, Vos P, et al. (1996). PCR-based fingerprinting using AFLPs as a tool for studying genetic relationships in Lactuca spp. Theor. Appl. Genet. 93: 1202-1210.

Huang J and Li G (2009). Double-stranded RNA elements and their association with pathogenicity of Sclerotinia sclerotiorum. Acta Phytopathol. Sin. 39: 30-35.

Jana T, Sharma TR and Singh NK (2005). SSR-based detection of genetic variability in the charcoal root rot pathogen Macrophomina phaseolina. Mycol. Res. 109: 81-86.

Jiang H, Liao B, Ren X, Lei Y, et al. (2007). Comparative assessment of genetic diversity of peanut (Arachis hypogaea L.) genotypes with various levels of resistance to bacterial wilt through SSR and AFLP analyses. J. Genet. Genomics 34: 544-554.

Kim HS, Hartman GL, Manandhar JB and Graef GL (2000). Reaction of soybean cultivars to Sclerotinia stem rot in field, greenhouse, and laboratory evaluations. Crop Sci. 40: 665-669.

Li ZQ, Wang YC, Chen Y and Zhang JX (2009). Genetic diversity and differentiation of Sclerotinia sclerotiorum populations in sunflower. Phytoparasitica 37: 77-85.

Li P, Cao S, Dai YL, Li XL, et al. (2012). Genetic diversity of Phytophthora capsici (Pythiaceae) isolates in Anhui Province of China based on ISSR-PCR markers. Genet. Mol. Res. 11: 4285-4296.

Maxwell DP and Lumsden RD (1970). Oxalic acid production by Sclerotinia sclerotiorum in infected bean and in culture. Phytopathology 60: 1395-1398.

McGregor CE, Lambert CA, Greyling MM and Louw JH (2000). A comparative assessment of DNA fingerprinting techniques (RAPD, ISSR, AFLP and SSR) in tetraploid potato (Solanum tuberosum L.) germplasm. Euphytica 113: 135-144. 
Mert-Türk F, Ipek M, Mermer D and Nicholson P (2007). Microsatellite and morphological markers reveal genetic variation within a population of Sclerotinia sclerotiorum from oilseed rape in the Çanakkale Province of Turkey. $J$. Phytopathol. 155: 182-187.

Meyer W, Mitchell TG, Freedman EZ and Vilgalys R (1993). Hybridization probes for conventional DNA fingerprinting used as single primers in the polymerase chain reaction to distinguish strains of Cryptococcus neoformans. J. Clin. Microbiol. 31: 2274-2280.

Mukai Y, Suyama Y, Tsumura Y, Kawahara T, et al. (1995). A linkage map for sugi (Cryptomeria japonica) based on RFLP, RAPD, and isozyme loci. Theor. Appl. Genet. 90: 835-840.

Purdy LH (1979). Sclerotinia sclerotiorum: history, diseases and symptomatology, host range, geographic distribution, and impact. Phytopathology 69: 875-880.

Rohlf FJ (2000). NTSYS-pc: Numerical Taxonomy and Multivariate Analysis System. Version 2.1 Manual. Applied Biostatistics, New York.

Rong SB (2009). Analysis of situation and strategies of rapeseed production in Anhui Province. Chin. Seed Ind. 9: 19-20.

Stewart CN Jr and Via LE (1993). A rapid CTAB DNA isolation technique useful for RAPD fingerprinting and other PCR applications. Biotechniques 14: 748-750.

Subbarao K (1998). Progress toward integrated management of lettuce drop. Plant Dis. 82: 1068-1078.

Sun JM (2005). Determination of Morphology, Pathogenicity and Genetic Diversity of Sclerotinia sclerotiorum (Lib.) de Bary Isolates From Different Origins. Doctoral thesis, Department of Biochemistry and Molecular Biology, China Agricultural University, Beijing, 79-85.

Sun JM, Irzykowski W, Jedryczka M and Han FX (2005). Analysis of the genetic structure of Sclerotinia sclerotiorum (Lib.) de Bary populations from different regions and host plants by random amplified polymorphic DNA markers. J. Integr. Plant Biol. 47: 385-395.

Tahtamouni MEW, Hameed KM and Saadoun IM (2006). Biological control of Sclerotinia sclerotiorum using indigenous chitinolytic actinomycetes in Jordan. Plant Pathol. J. 22: 107-114.

Wegulo SN, Yang XB and Martinson CA (1998). Soybean cultivar responses to Sclerotinia sclerotiorum in field and controlled environment studies. Plant Dis. 82: 1264-1270.

Williams B, Kabbage M, Kim HJ, Britt R, et al. (2011). Tipping the balance: Sclerotinia sclerotiorum secreted oxalic acid suppresses host defenses by manipulating the host redox environment. PLoS Pathog. 7: e1002107.

Yu X, Wang G and Zhang N (2006). The polymorphism of nuclear DNA of Sclerotinia sclerotiorum from different areas in our country. J. Hebei N. Univ. 122: 24-26.

Zietkiewicz E, Rafalski A and Labuda D (1994). Genome fingerprinting by simple sequence repeat (SSR)-anchored polymerase chain reaction amplification. Genomics 20: 176-183. 